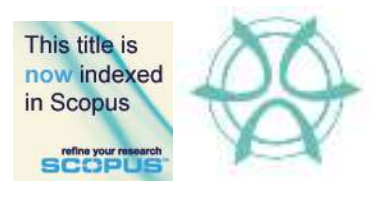

\title{
THE FUNCTIONS OF LANDSCAPE IN SCHOOL LEARNING PROCESS
}

\author{
Salina Mohamed Ali ${ }^{1}$, Noriah Othman ${ }^{2}$, Faridatul Akma Abdul Latif ${ }^{3}$, \\ Abd. Hair Awang ${ }^{4}$, Katiman Rostam ${ }^{5}$ \\ ${ }^{1,2,3}$ Faculty of Architecture, Planning \& Surveying, \\ UNIVERSITI TEKNOLOGI MARA \\ ${ }^{4,5}$ School of Social, Development \& Environment, FSSK, \\ UNIVERSITI KEBANGSAAN MALAYSIA
}

\begin{abstract}
This article seeks to identify the function of the schools' landscapes in the learning process. For this study, primary data were collected through field observations using a checklist. 104 schools within the Klang Valley-Langat area were randomly selected. Structured interview sessions were conducted with school managers and secondary data were obtained from various agencies. Results showed that the function of landscapes in assisting learning was at a high score $(47.1 \%)$. Scores of rural schools were at 51.6 percent ahead of urban schools $(45.2 \%)$. There was a significant relationship between the function of landscapes assisting in the learning process and academic achievement at the school level at 0.01 with a Chi-square value of 35.993. Pearson product-moment correlation test results showed a significant correlation in weak and moderate levels of landscape functions assisting in the process of learning and academic achievements. This proved that the landscape had an important role in the learning process. It is hoped that this study will create awareness among the school's community.
\end{abstract}

Keywords: Landscape functions, assisting the learning process, landscaping components, Klang Valley-Langat

\footnotetext{
${ }^{1}$ Lecturer at University Teknologi MARA Email: salina77775@yahoo.com
} 
Salina Mohamed Ali, Noriah Othman, Faridatul Akma Abdul Latif, Katiman Rostam, Abd. Hair Awang

The Functions of Landscape in School Learning Process

\section{INTRODUCTION}

Compared to other current issues in schools, such as curriculum development, learning in schools, students' nutrition and diet, as well as issues of students' obesity, not many other studies have been conducted on the function of landscapes in the schools' environment. This is not consistent with the landscape planning of schools, which provides an opportunity for the schools' management to beautify the schools' environment to enhance the learning experience. The school's management still has a little awareness of the importance and function of the landscape environment in supporting the learning process (Zaleha Abdullah, 2014). In an attempt to give some insights to this issue, the present article seeks to identify the function of the schools' landscapes in the learning process (Cody \& Heather, 2017).

The role or function of the schools' landscape in preserving the environment should be from the schools' level. It is vital to have a clear way of preserving the schools' environment. Recognising the circumstances that there are problems in developing landscaping in schools, the government has its plans to permeate these problems (Salina et al., 2014). Several programmes are introduced to liven up the surrounding and environment in schools. These programmes are held at municipality, district and also, state levels. Programmes are introduced and organised via Ministry of Education, Malaysia in ensuring every school performs its position in developing its own landscaping. Ministry of Education introduced and launched its Keselamatan, Kebersihan dan Keceriaan (3K) Programme in 1993. This 3K programme stresses on the safety, cleanliness and beautifying the schools (Rohhayati, 2008).

Landscapes around the school's compound either directly or indirectly assist in the learning process (Dyment \& Bell, 2007; Loebach \& Gilliland, 2014; Van Dijk-Wesselius et al., 2018). This can be seen in terms of cognitive, psychomotor and affective skills through various spaces for leisure, socialising and interactions with landscaping components during the indoor or outdoor revision of lessons. Besides that, the landscaped environment may be used to conduct related subject matters, such as Geography, Biology and Chemistry. For example, trees can provide shade to reduce the amount of sunlight on the building and the ground to moderate the temperature of the environment (Alamah Misni, 2013). Microclimatic conditions of areas surrounded by trees are usually more comfortable when compared to open areas. Plants also act as a green lung to the schools' environment by absorbing carbon dioxide and by releasing oxygen. This indicates that green areas provide more oxygen, which is vital for the school's environment in creating responsive conditions for mental development. Evidence of a theory of attention restoration (Berman et al., 2008; Kaplan, 1995; Kaplan \& Berman, 2010) associates the green environment to a calming of the mind and an increased concentration, especially to students who are studying. On the other 
hand, trees are able to reduce extreme heat, thereby, reducing the usage of airconditioning in schools.

The ambient atmosphere outside classrooms stimulates the mind and encourages the learning process. Past studies indicated that some plants can stimulate the thinking process through regular interactions with students $(\mathrm{Ke}-$ Tsung, 2009; Paddl \& Gillil, 2016). The concept of an attractive landscape can also provide opportunities for students, teachers and visitors to obtain information about its flora species, function and diversity of plants within the school environment (Clevenger et al., 2020). As a result, the more the components and elements of the landscape that can be used to support and facilitate the learning process, either directly or indirectly, the better and higher the quality of the school's landscape and functionality (Chawla et al., 2014; Robert \& Robert, 2020).

From an interview with one of the school principals, he felt that hard landscaping, such as gazebos, park benches and tables can be used by the students to discuss, analyse and facilitate the learning process. Hard landscapes, such as information signages and tree descriptions can provide invaluable knowledge to the students while creating awareness about the importance of protecting the environment. Signages of reminders and life's advice containing verses from the Quran form a contributing element to the character-building of the students to respect their teachers, friends and parents.

Soft landscaping components consisting of a large, medium and small trees along with fruit trees can cool temperatures within the schools and encourage the students to review their lessons in the school compound. MoogkSoulis (2002) reported that trees can be used to provide shades against surfaces, as well as to act as a barrier to hot winds and to create cool air instead.

Researchers also observed that artificial landscapes consisting of fish ponds and cascading ponds can provide therapeutic facilities to the school's occupants (Kopeva et al., 2017). Sounds of water elements soothe the mind, providing the ideal environment for the acumen of knowledge (Kelz et al., 2013). However, the presence of koi fish, turtles and dragonflies can cultivate a sense of compassion for animals, as well as care for the school environment. Students enjoy sitting near ponds during the breaks to feed the fish while playing with friends.

A growing literature body suggests that individuals need a connection with natural environment for selves' well-being. Conversely, at this point, the young children are increasingly becoming more separated from their natural surrounding as their access to the surroundings are gradually diminishing (Dowdell et al., 2011; Robert \& Robert, 2020). The significance of schooling and prior-to-school settings in correlating children with natural surroundings had been recognised. Furthermore, the yielded outcomes suggested that natural outdoor environments expanded the children's imaginative act and the 
Salina Mohamed Ali, Noriah Othman, Faridatul Akma Abdul Latif, Katiman Rostam, Abd. Hair Awang The Functions of Landscape in School Learning Process

developmental of pro-behavioural relationships, as well as permitted the natural environment as a place of play-learning. Dowdell et al. (2011) concluded that in order to make use of effective outdoor play-learn settings, early childhood learning centres ought to provide the children with an access to the natural outdoor environment and educators who are supportive towards children developmental relationship with the nature.

The key intention in this study is to identify the function of the schools' landscapes in the learning process. A conducive landscaped environment may directly or indirectly help the learning process through a variety of ways, such as providing spaces for leisure, socialising, interacting with components of the landscape, or even the revision of lessons outside classrooms. The specific objectives of the study are to determine the benefaction of the soft and hard landscapes in the learning process to increase the schools' academic achievement.

\section{LOCATION AND METHOD}

The study was conducted in schools located at urban and rural areas in Klang Valley - Langat, especially schools located in the state of Selangor. Schools located in the Shah Alam and Subang Jaya Municipality in the Petaling district, Selayang City Council in Gombak and Klang City Council in the Klang district were selected to represent schools in urban areas. Schools in the district of Hulu Langat and Sepang were chosen to represent schools in suburban and rural areas. Classification of urban and rural schools was based on criteria set by State's Department of Education and the National Department of Education. The Klang Valley-Langat districts in Selangor were chosen for this study due to several reasons. First, its location is within areas of rapid urbanisation with the highest population growth in Peninsular Malaysia. Second, schools within this region experience rapid modernisation since they are within the vicinity of innovation, which is at the extended metropolis of Kuala Lumpur. Third, the size of the available landscapes in Klang Valley-Langat is limited and narrower due to land shortage and escalating land prices that impact development patterns (Katiman Rostam, 2006; Katiman Rostam, et al., 2010; The Federal Territory Development and the Klang Valley Planning Division, 2004).

This study used primary and secondary data. Primary data were collected from inspection and observation at schools. For secondary data, they were in the form of records, documents and other official statistics that were gathered from various departments and agencies, particularly State and Federal Territory Department of Education, as well as Ministry of Education. Basic data published by the Department of Statistics were also used. Information on students and teachers from the selected schools were also obtained. There were tertiary sources used that included books, journals, technical reports, theses, and dissertations. Before the formation of the structured interview form, references of procedures were obtained. These references included literature review and 
expert feedback in the field of landscaping, landscape architects from National Department of Landscape, experts in the field of education, experienced school teachers, as well as landscape consultants with deep knowledge and experience in the field.

Structured interview was conducted with top school administrators involved in the development and management of the school landscapes. The number of school administrators interviewed for this study consisted of a total of 104 respondents. The selection of sample size was based on Krejcie and Morgan's (1970) table which denominated the sample required from a population for structured interview which was analysed using the SPSS software. The results were discussed in the next section.

The functional quality of the landscapes in schools was evaluated based on the functional aspects concerning the learning process. The basis of evaluation was on the relative merits of each component of the hard, soft and artificial landscapes, as well as facilities, flora and fauna using a Likert scale, consisting of 'not related', 'related' and 'highly related'. Overall, the quality of the functionality of the schools' landscape in the Klang Valley-Langat was divided into three categories: low, medium and high.

\section{RESULTS AND DISCUSSIONS}

In assessing the function of learning, majority of schools were in the category of high scores (47.1\%) (see Table 1). Rural schools were at 51.6 per cent, ahead of the urban schools (45.2\%). This suggested that school administrators of rural schools were more sensitive to the functional components of hard, soft and artificial landscaping, as well as in the usage of the external learning environment. Only 9.6 per cent of schools were in a low category. Schools that were in the low category were unable to maximise their landscapes as a learning tool due to limited finances and other financial constraints.

Table 1: Functions of landscape in the learning process

\begin{tabular}{|c|c|c|c|c|c|c|c|}
\hline Score & \multirow[t]{2}{*}{ Category } & \multicolumn{2}{|l|}{ Urban } & \multicolumn{2}{|l|}{ Rural } & \multicolumn{2}{|l|}{ Total } \\
\hline Quality & & Frequency & $\%$ & Frequency & $\%$ & Frequency & $\%$ \\
\hline $\begin{array}{l}123- \\
153\end{array}$ & Low & 7 & 9.6 & 3 & 9.7 & 10 & 9.6 \\
\hline $\begin{array}{l}154- \\
184\end{array}$ & Medium & 33 & 45.2 & 12 & 38.7 & 45 & 43.3 \\
\hline $\begin{array}{l}185- \\
216\end{array}$ & High & 33 & 45.2 & 16 & 51.6 & 49 & 47.1 \\
\hline Total & - & 73 & 100.0 & 31 & 100.0 & 104 & 100.0 \\
\hline
\end{tabular}


Salina Mohamed Ali, Noriah Othman, Faridatul Akma Abdul Latif, Katiman Rostam, Abd. Hair Awang The Functions of Landscape in School Learning Process

For high category, samples of schools located at urban areas located in Shah Alam, Sekolah Menengah Kebangsaan (SMK) 101 with a score of 215 were selected. This was followed by Sekolah Menengah Kebangsaan (SMK) 78 with a score of 207 located in Subang Jaya and Sekolah Menengah Kebangsaan (SMK) 1 with a score of 207 located in Semenyih. Samples were also taken from a rural school in the district of Hulu Langat. Observations in these schools identified that facility of parking, walkways, lighting, and litter bins received the highest scores as compared to other components. Experts from the Ministry of Education, State's Department of Education and landscape architects from National Department of Landscape elucidated that facilities, such as walkways, toilets, litter bins, and others used by the students were crucial in the learning process. It was observed that the facility component was the most frequently found in almost all schools in the study area.
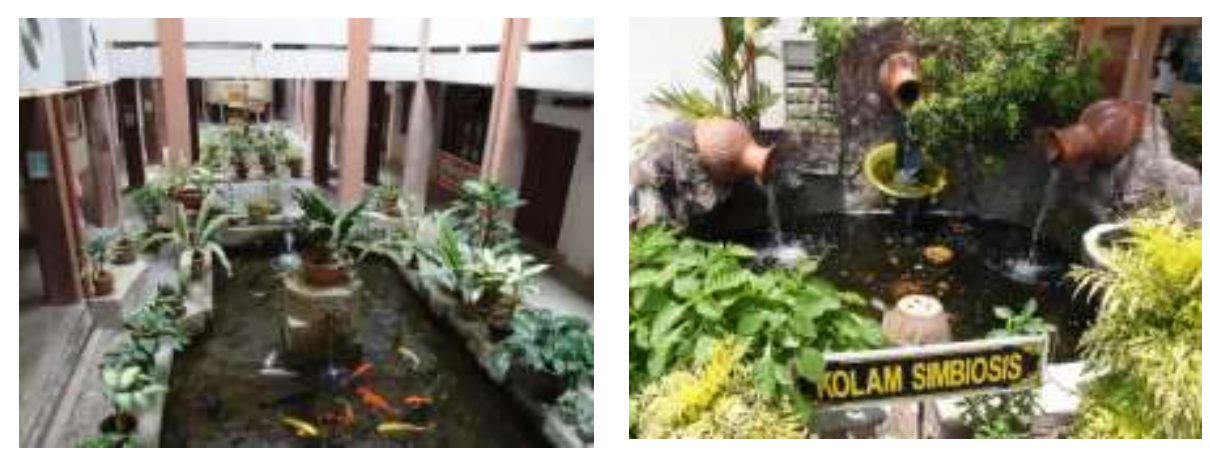

Figure 1: The water element and plants create a sense of comfortable. (Sekolah Menengah Kebangsaan 43 and 78) Source: Author, 2019.

The flora component scored the second-highest after the facility. Most urban schools prioritised the cultivation of plants to compensate for the hot climate in the city (see Figure 1). This could serve as shade trees that absorbed heat (Alamah Misni, 2013; Lanza et al., 2020), cooled the school and provided shade for the students (Akbari \& Taha, 1992). Comfortable shade trees increased enthusiasm and encouraged the students to gather and discuss extra-curricular activities, sports and recreation (Moogk-Soulis, 2002).

For rural schools, the hard landscapes were of a more important function in assisting the students. Many low-income families did not have basic facilities, such as furniture or sufficient recreational facility or area. Thus, many rural students used the schools' environment as their second home to study and complete their homework. They also used the schools' environment for recreation. 
PLANNING MALAYSIA

Journal of the Malaysia Institute of Planners (2020)

Table 2 shows the different learning activities held in the schools. For activities conducted outside the classroom, mean activity of planting flowers obtained the highest value (6.98), followed by camping (6.85), cooking (5.88), carpentry and painting (5.63), as well as others. The data were irregularly scattered among one another. All data were in the standard deviation of between 0.800 to 5.500 units. This demonstrated that the school environment was used for learning and co-curricular activities (see Figure 2).

Table 2: Learning activities conducted in schools

\begin{tabular}{llll}
\hline Outdoor Classroom & N & Min & Standard Deviation \\
\hline Sitting down to discuss & 89 & 2.70 & 1.991 \\
\hline Revision of subjects & 81 & 3.41 & 2.042 \\
\hline Experiments & 70 & 4.34 & 2.126 \\
\hline Physical education & 103 & 1.50 & 0.862 \\
\hline Observations of plants & 83 & 4.53 & 1.896 \\
\hline Observations of insects and its habitat & 76 & 5.05 & 1.825 \\
\hline Relating subject matters to the & 93 & 4.30 & 2.004 \\
schools' environment & & & \\
\hline Green Earth and Environment Club & 89 & 4.70 & 1.921 \\
\hline Gardening or vegetables & 59 & 5.08 & 2.238 \\
\hline Flower planting & 82 & 6.98 & 5.484 \\
\hline Recycling & 94 & 5.37 & 2.145 \\
\hline Carpentry and painting & 89 & 5.63 & 2.145 \\
\hline Cooking & 73 & 5.88 & 2.248 \\
\hline Camping & 99 & 6.85 & 1.798 \\
\hline Marching & 102 & 3.45 & 2.132 \\
\hline Uniform bodies & 104 & 2.88 & 1.585 \\
\hline & & & Source: Author, 2019
\end{tabular}
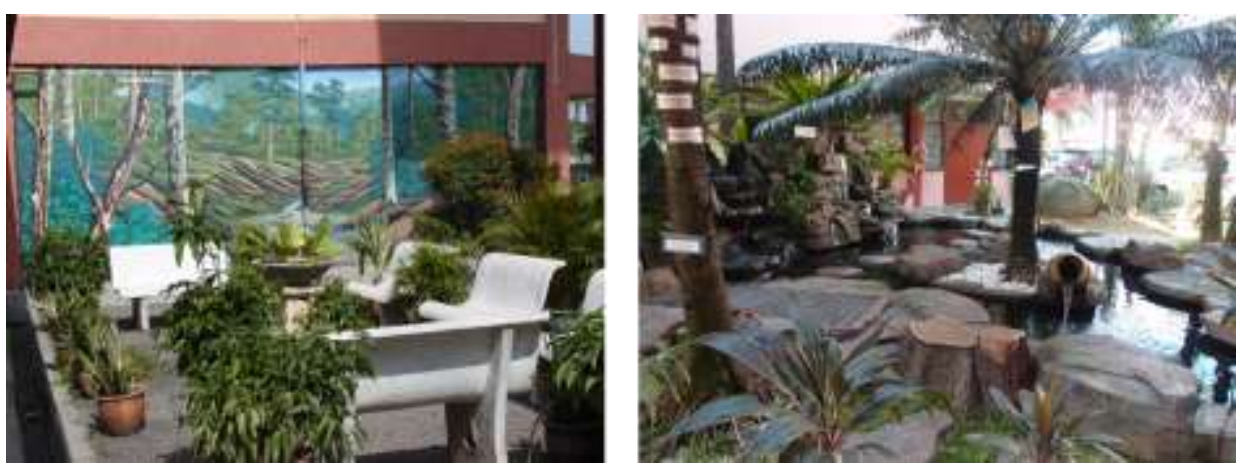

Figure 2: The different learning activities held in the schools that use outdoor class. (Sekolah Menengah Kebangsaan 72 and 85).

$$
\text { Source: Author, } 2019 .
$$


Salina Mohamed Ali, Noriah Othman, Faridatul Akma Abdul Latif, Katiman Rostam, Abd. Hair Awang

The Functions of Landscape in School Learning Process

\section{RELATIONSHIP BETWEEN FUNCTIONS OF LANDSCAPE AND SCHOOLS' ACHIEVEMENT}

Each landscape component was selected by hard, soft or artificial landscapes, facilities, fauna, and flora based on certain scores. Table 3 displays the mean scores of the dependent variable, in assisting the learning process. The cognitive aspects of the landscape functions had the highest mean score with facility component (54.80), followed by flora with a mean score of 43.59 and hard landscapes with a mean score of 33.94. This proved that flora of trees with shade, fruit trees, shrubs, ground cover, and plants were more prominent components used by the students during their studies in identifying the names and functions of plants in relation to Science subjects, Civil studies, Geography, Islamic Education, and Arts. The standard deviation values of hard landscapes, flora, and fauna were found to be high.

Table 3: Mean (dependent variables) representing the functional landscapes in assisting the learning process

\begin{tabular}{lll}
\hline Landscape Components & Min & Standard Deviation \\
\hline Hard landscapes & 33.94 & 6.270 \\
\hline Soft landscapes & 21.83 & 3.230 \\
\hline Artificial landscapes & 4.47 & 1.954 \\
\hline Facilities & 54.80 & 2.120 \\
\hline Fauna & 23.04 & 4.435 \\
\hline Flora & 43.59 & 8.402 \\
\hline Total & 180.20 & 18.270 \\
\hline \multicolumn{1}{c}{ Source: Author, 2019 } & &
\end{tabular}

By using the Chi-square statistics (Pearson product-moment correlation), the variable function of the landscape in assisting the learning process had been tested against variable segments of academic achievement. Table 4 illustrates the relationship between the function of landscapes in the learning process and that of academic achievement. It was demonstrated that the landscapes in assisting the learning process were in the high category (79.6\%). There was also a significant relationship between the function of landscapes in assisting the process of learning and academic achievement at the school level of 0.01 with the Chi-square value of 35.993 .

Table 4: Relationship (Chi-Squared) between landscape functions (learning) and academic achievements (total)

\begin{tabular}{lllllll}
\hline Category of & \multicolumn{5}{l}{ Scores for Functional Landscapes (Learning) } \\
\cline { 2 - 7 } $\begin{array}{l}\text { Achievement for } \\
\text { School }\end{array}$ & High & Medium & Low & \\
\cline { 2 - 6 } (Academic) & No of & No of & $\%$ & No & $\%$ \\
& Schools & & Schools & Schools. &
\end{tabular}


PLANNING MALAYSIA

Journal of the Malaysia Institute of Planners (2020)

\begin{tabular}{lllllll}
\hline High & 39 & 79.6 & 23 & 51.1 & 1 & 10.0 \\
\hline Medium & 10 & 20.4 & 20 & 44.4 & 5 & 50.0 \\
\hline Low & 0 & 0.0 & 2 & 4.4 & 4 & 40.0 \\
\hline Total & 49 & 100.0 & 45 & 100.0 & 10 & 100.0
\end{tabular}

At the significance level of $\mathrm{p}<0.01, \mathrm{df}=4$, Chi-square and Pearson 35.993

A more detailed test was performed between the scores of the functional components of the landscape in assisting the school's academic achievements (see Table 5). The test results revealed a significant relationship at the weak and moderate levels (Guilford, 1956) between the total score of the functional landscape in assisting the learning process and that of academic achievements of schools $(r=0.504, p<0.01)$. In general, these tests proved that there was a relationship between the schools' landscapes with the learning process in the Klang Valley-Langat. The test results also exhibited a significant reading for the landscapes assisting in the learning process by the achievements of Malaysia Certificate of Education (SPM) $(\mathrm{r}=0.355, \mathrm{p}<0.01)$, Lower Secondary Assessment (PMR) $(r=0.370, p<0.01)$ and awards for quality $(r=0.243, p$ $<0.01$ ). This implied that the landscapes assisted in the learning process and had a significant relationship with all the segments of academic achievement.

Table 5: Pearson correlation of the relationship between landscape functions in assisting the learning process and academic achievement

\begin{tabular}{lccl}
\hline Relationship & r & Sig & $\begin{array}{l}\text { Relationship } \\
\text { Level }\end{array}$ \\
\hline $\begin{array}{l}\text { Landscape functions (assist learning) with } \\
\text { SPM achievements }\end{array}$ & $0.355^{* *}$ & 0.000 & Weak \\
\hline $\begin{array}{l}\text { Landscape functions (assist learning) with } \\
\text { PMR achievements }\end{array}$ & $0.370^{* *}$ & 0.000 & Weak \\
\hline $\begin{array}{l}\text { Landscape functions (assist learning) with } \\
\text { awards for quality }\end{array}$ & $0.243^{*}$ & 0.013 & Weak \\
\hline $\begin{array}{l}\text { Landscape functions (assist learning) with } \\
\text { academic achievement (overall) }\end{array}$ & $0.504^{* *}$ & 0.000 & Intermediate \\
\hline
\end{tabular}

Note: ** Correlation relationship significant at level 0.01 (two-tailed); ${ }^{*}$ Correlation is significant at the 0.05 level (two-tailed).

\section{CONCLUSION}

Overall, there was a significant relationship at moderate and high levels of landscape functions towards the learning process and academic achievements of the schools. At this juncture, the relationship with landscaping functions in facilitating the learning process consisted of several components of hard landscaping elements. These hard landscaping elements comprised gazebos, pergolas, benches, garden tables, signages, flower vases, and soft landscaping elements. Pertaining to soft landscaping elements, they included shade trees, 
Salina Mohamed Ali, Noriah Othman, Faridatul Akma Abdul Latif, Katiman Rostam, Abd. Hair Awang The Functions of Landscape in School Learning Process

shrubs, fruit trees, ground covers, and other herbal plants. It is hoped if the school's landscapes are better managed. This is particularly pertinent for the hard and soft elements of landscaping, the quality and its function because it is expected to increase. In effect, it is also expected to increase the school's academic achievement. Teachers are also able to use the school's garden for Science, Geography and Arts education. Artificial landscapes, such as fish ponds or cascading water features can also be used by the teachers to provide examples of aquatic habitats. For students, they will have the opportunity to examine the hard landscape closely by utilising hard landscape elements, such as benches and tables, as well as gazebos for discussions. This demonstrates that landscapes have an important role in the learning process of schools.

\section{ACKNOWLEDGMENTS}

The authors wish to extend their sincere thanks to Ministry of Education, Department of Education Selangor, and the schools' principals for taking part in this research and for granting permission to conduct interview sessions and observations. Besides that, the authors would like to extend their appreciation and gratitude to Universiti Teknologi MARA for granting Lestari Grant to complete this article with a RMI file no: 600-IRMI 5/3/LESTARI (043/2018).

\section{REFERENCES}

Akbari, H., \& Taha, H. (1992). The impact of trees and white surfaces on residential heating and cooling energy use in four Canadian cities. Energy, 17(2), 141-149.

Alamah Misni. (2013). Modifying the Outdoor Temperature around Single-Family Residences: The influence of landscaping. Procedia - Social and Behavioral Sciences, 105, 664-673.

Berman, M. G., Jonides, J., \& Kaplan, S. (2008). The cognitive benefits of interacting with nature. Psychological Science, 19, 1207.

Chawla, L., Keena, K., Pevec, I., \& Stanley, E. (2014). Green schoolyards as havens from stress and resources for resilience in childhood and adolescence. Health Place, 28, $1-13$.

Clevenger, K. A., Wierenga, M. J., Howe, C. A., \& Pfeiffer, K. A. (2020). A systematic review of child and adolescent physical activity by schoolyard location. Kinesiology Review, 9(2), 147-158.

Cody, B., \& Heather, A. S. (2017). Green urban landscapes and school-level academic performance. Landscape and Urban Planning, 160, 16-27.

Dowdell, K., Gray, T., \& Malone, K. (2011). Nature and its influence on children's outdoor play. Australian Journal of Outdoor Education, 15(2), 24-35.

Dyment, J. E., \& Bell, A. C. (2007). Active by design: Promoting physical activity through school ground greening. Children's Geographies, 5(4), 463-477.

Guilford, (1956). Fundamental statistic in psychology and education. New York: McGraw-Hill.

Kaplan, S. (1995). The restorative benefits of nature: Toward an integrative framework. Journal of Environmental Psychology, 15, 169-182. 
Kaplan, S., \& Berman, M. G. (2010). Directed attention as a common resource for executive functioning and self-regulation. Perspectives on Psychological Science, 5, 43-57.

Katiman Rostam. (2006). Migrasi ke kawasan pinggiran Wilayah Metropolitan Lembah Klang. Akademika, 68, 3-27.

Katiman Rostam, Mochamad Rosul., Er, A. C., Abdul Rahim Mohd Nor, Zaini Sakawi., Norazuan Md. Hashim, \& Aishah@Esah Hj. Muhammad. (2010). Pembandaran dan rebakan bandar di pinggir Wilayah Metropolitan Klang-Langat. Geografia: Malaysian Journal of Society and Space, 6(2), 37-50.

Ke-Tsung, H. (2009). Influence of limitedly visible leafy indoor plants on the psychology, behavior, and health of students at a junior high school in Taiwan. Environment and Behavior, 41(5), 658-692.

Kelz, C., Evans, G., \& Röderer, K. (2013). The restorative effects of redesigning the schoolyard: A multi-methodological, quasi-experimental study in rural Austrian middle schools. Environment and Behavior, 47, 119-139.

Kopeva, A., Khrapko, O., \& Ivanova, O. (2017). Landscape planning of schoolyards. IOP Conf. Series: Materials Science and Engineering, 262, 012145 doi:10.1088/1757$899 X / 262 / 1 / 012145$.

Krejcie, R. V., \& Morgan, D. W. (1970). Determining sample size for research activities. Educational and Psychological Measurement, 30, 607-610.

Lanza, K., Alcazar, M., Hoelscher, D. M., Kohl III, H. W. (2020). Effects of trees, gardens, and trails on heat index and child health: Design and methods of the Green Schoolyards Project. Research Square, 1-17.

Loebach, J., \& Gilliland, J. (2014). Free Range Kids? Using GPS-Derived Activity Spaces to Examine Children's Neighborhood Activity and Mobility. Environment and Behavior, 48, 421-453.

Moogk-Soulis, C. (2002). Schoolyard heat islands: A case study in Waterloo, Ontario. Proceedings from Canadian Urban Forest Conference, 1-7. Retrieved from http://www.tcf-fca.ca/cufc5/papers/Moogk-Soulis.pdf.

Paddl, E., \& Gillil, J. (2016). Orange is the new green: Exploring the restorative capacity of seasonal foliage in schoolyard trees. International Journal of Environmental Research and Public Health, 13(5), 497.

Robert, D. B., \& Robert, C. C. (2020). Evidence-based landscape architecture for human $\begin{array}{llll}\text { health and well-Being. } & \text { Sustainability, }\end{array}$ https://doi.org/10.3390/su12041360.

Rohhayati, N. (2008). Student perception of school landscape and its influence on learning experience at the award-winning secondary school in Kelantan, Malaysia. (Unpublished Master Thesis.) Selangor: Universiti Putra Malaysia.

Salina, M. A., Katiman, R., \& Hair, A. A. (2014). Characteristics of landscape and surrounding qualities of schools in Klang Valley. Asian Journal of Multidisciplinary Studies, 2(6), 61.

The Federal Territory Development and the Klang Valley Planning Division. (2004). Retrieved from: https:/www.researchgate.net/figure/The-location-of-the-KlangValley-in-Peninsular-Malaysia-Source-The-Federal- Territory_fig1_270706854.

Van Dijk-Wesselius, J. E., Maas, J., Hovinga, D., Van Vugt, M. V. D. B. A., \& Van den Berg, A. E. (2018). The impact of greening schoolyards on the appreciation, and 
Salina Mohamed Ali, Noriah Othman, Faridatul Akma Abdul Latif, Katiman Rostam, Abd. Hair Awang

The Functions of Landscape in School Learning Process

physical, cognitive and social-emotional well-being of schoolchildren: A prospective intervention study. Landscape and Urban Planning, 180, 15-26.

Zaleha Abdullah (2014). Activity theory as analytical tool: A case study of developing student teachers' creativity in design. Procedia - Social and Behavioral Sciences, $131,70-84$.

Received: $15^{\text {th }}$ May 2020. Accepted: $1^{\text {st }}$ Sept 2020 